\title{
Ethics at the Intersection of Crisis Translation and Humanitarian Innovation ${ }^{1}$
}

\author{
Matthew Hunt \\ Associate Professor and Director of Research, School of Physical and Occupational Therapy, McGill University, Center for \\ Interdisciplinary Rehabilitation Research; matthew.hunt@mcgill.ca
}

Sharon O'Brien

Associate Professor, School of Applied Language and Intercultural Studies, ADAPT Research Centre; Centre for Translation and Textual Studies, Dublin City University; sharon.obrien@dcu.ie

\section{Patrick Cadwell}

Assistant Professor, School of Applied Language \& Intercultural Studies, Centre for Translation and Textual Studies, Dublin City University; patrick.cadwell@dcu.ie

\section{Dónal P. O’Mathúna}

Associate Professor, School of Nursing, Psychotherapy \& Community Health, Dublin City University; College of Nursing, The Ohio State University; omathuna.6@osu.edu

\begin{abstract}
Language and its translation are important operational concerns in humanitarian crisis response. Information sharing, coordination, collaboration and relationship-building all revolve around the ability to communicate effectively. However, doing so is hampered in many humanitarian crises by linguistic differences and a lack of access to adequate translation. Various innovative practices and products are being developed and deployed with the goal of addressing these concerns. In this theoretical paper, we critically appraise the ethical terrain of crisis translation and humanitarian innovation. We identify ethical issues related to three broad themes. First, we foreground questions of justice in access to translation and its prioritisation in contexts of widespread and pressing needs. Second, we consider the relationship between humanitarian ethics and the ethics of crisis translation. We argue for the importance of attending to epistemic justice in humanitarian crisis response, and consider how Ricoeur's conception of linguistic hospitality provides insights into how relationships in humanitarian settings can be understood through the lens of an ethics of exchange while also acknowledging the steep asymmetries that often exist in these contexts. Finally, we identify issues related to how translation innovations intersect with humanitarian values and humanitarians' ethical commitments.
\end{abstract}

Keywords: ethics, humanitarian crises, innovation, language, translation, translation technology

\section{Introduction}

The 2010 Haiti earthquake has been described as a 'game changer' for the implementation of technologies in humanitarian response (Sandvik, 2014: 26). Established and emergent information and communication technology (ICT) applications were employed in the earthquake's aftermath and 'relief efforts quickly became a living laboratory for new applications of SMS texting, interactive online maps and radio-cell phone hybrids' (Nelson et al., 2010: 15). Language and translation were important components of these ICT applications, and for relief efforts more broadly, since most international responders did not speak Creole or

\section{MANCHESTER} 1824

Manchester University Press 
French. Thousands of Creole- and French-speaking volunteers - predominantly Haitian nationals and members of the Haitian diaspora - translated incoming SMS messages and telephone calls, which were then relayed to groups on the ground providing assistance and integrated into crowd-sourced live maps, which provided close to real-time information about the location of injured persons and infrastructure damage (Harvard Humanitarian Initiative, 2011; Munro, 2013). To amplify the capacity for translation, a group from Microsoft, Stanford University and Carnegie Mellon University also created a Machine Translation (MT automatic, computer translation) engine from Creole to English (Lewis et al., 2011). These initiatives proved useful in overcoming some language barriers, though others persisted (Munro, 2013).

The Haiti earthquake illustrates the multilingual nature of humanitarian crises and the importance of translation, as well as the close connection between language and humanitarian ICT innovations. These features are not unique to the Haiti earthquake, and many crises occur in contexts where linguistic diversity is greater. A recent example of the need for translation and interpreting in humanitarian response is the Rohingya refugee crisis. In August 2018, Translators without Borders (TWB) surveyed a sample of refugees in the Kutupalong-Balukhali camp (407 respondents) to better understand their language and information needs (Hasan, 2018). TWB found that language barriers and low access to media left many Rohingya refugees without the crucial information they needed to get support and make informed choices. Communication was made even more difficult by the fact that the Rohingya language lacks a universally accepted script, and 66 per cent of those surveyed could not read or write in any language. This suggests that verbal communication and simple visual messaging needs to be considered. However, written translation also plays a crucial role, since those who can read expressed a preference for information to be presented in written leaflets that are portable and can be referred to on more than one occasion. Linguistic diversity and appropriate formats have also been identified as communicative challenges for humanitarian monitoring and evaluation in South Sudan, especially the 'large number of national languages spoken and low literacy rates' (Steets et al., 2016: 28). Research on Greece's migration crisis has illustrated a need for similar considerations. It has shown, too, that links between language and ICT innovations are complex. For instance, findings based on surveys with 202 refugees and migrants and 22 interviews with humanitarian workers indicated that, while social media were used extensively by refugees and migrants to network with family and friends, these platforms were not their preferred channel for receiving information on their situation in Greece, and refugees and migrants expressed preferences for written documents, posters or verbal communication (Ghandour-Demiri, 2017).

For these reasons, language and its translation are operational challenges for humanitarian action. The Sphere Handbook is a key reference point and identifies minimum standards for the field. It reinforces the importance of communicating in languages, formats and media that are easily understood, respectful and culturally appropriate for different members of the community, especially vulnerable or marginalized groups' (Sphere Association, 2018: 63). Providing 'interpreters and translators if needed' is also identified as a key action for sharing information with partners, coordination groups and other relevant actors (Sphere Association, 2018: 71). Conducting training for local service providers and providing documentation in local languages are also recommended.

Numerous groups are engaged in projects to increase the quality and reach of crisis translation. For interpreting (the spoken act of translation), the InZone project demands recognition. ${ }^{2}$ InZone has pioneered innovative approaches to multilingual communication and higher education in communities affected by conflict and crisis, including an online module, 'Rapid Response Humanitarian Interpreting', that provides insights into the basic techniques required to work as or with humanitarian interpreters. ${ }^{3}$ TWB is active in many crisis settings, mainly focused on written translation but increasingly addressing oral interpretation. ${ }^{4}$ Another example is the Red $\mathrm{T}$ organisation, which protects translators and interpreters operating in high-risk settings. ${ }^{5}$

With increased translation provision during crises, ethical concerns are being recognised (O'Mathúna et al., forthcoming). This theoretical article examines the ethical terrain of crisis translation and, in particular, ethical considerations associated with innovative translation products and practices in humanitarian crises. We begin by considering the ethical implications of linguistic diversity and access to translation in humanitarian crises. We then explore how the ethics of crisis translation offers a distinctive perspective from which to consider humanitarian ethics more broadly. The final section discusses ethical dimensions of innovative strategies and emergent ICTs for crisis translation. Across these sections, we identify five layers of ethical issues, which are summarised in Table 1 and divided into three broad themes.

\section{Language and Exclusion in Humani- tarian Crisis}

Definitions of crisis are much debated and vary in scope and underlying premises. Sellnow and Seeger (2013:4-20) 
Table 1 Ethical issues at the intersections of humanitarian action, crisis translation and innovation

Justice and access to translation during crises

1 Language translation as an ethical obligation during humanitarian crises

2 Priority setting for translation initiatives amidst other pressing humanitarian goals

Linking crisis translation and humanitarian ethics

3 Insights from the ethics of crisis translation for humanitarian ethics more broadly

Ethical implications of developing and implementing innovative crisis translation products or processes

4 The values likely to be upheld or challenged when particular innovations are pursued

5 Addressing unintended consequences of innovations and sustaining successful innovations

review influential definitions and identify three primary conditions for a crisis: violated expectations, posed threats and required responses. By adapting their work, we define a crisis as an event, or series of events, that is non-routine, poses a significant threat and requires a response to mitigate the harm. We note, too, that responding to a crisis may require external assistance which renders communication and coordination more difficult. With this definition of crisis in mind, we define 'crisis translation' as the act of transferring meaning and cultural encodings from one language/ cultural system to another, in written, oral or signed modes, before, during or after a crisis. We focus on humanitarian crises: situations of large-scale social disruption and elevated risks for health and well-being due to armed conflict, disaster or epidemic, and where population needs far exceed local capacities. Translation in humanitarian response settings is thus one category of crisis translation.

Crisis translation plays a crucial role in making information available to linguistically diverse groups. Communication and the flow of information is a critical priority in a crisis (Aitsi-Selmi et al., 2016; Fischer, 2008; Seeger, 2006). It flows in many directions: within the community (e.g. connecting family members), from government agencies and non-governmental organizations (NGOs) to the community (e.g. about how to access services or stay safe), from the population to NGOs (e.g. feedback about services or information about people who have been injured or require help) and for coordination of aid providers. Access to information has been described as a right of populations affected by crisis (see, O'Brien et al., 2018). It has also been suggested that information constitutes a basic humanitarian good alongside food, water, shelter and healthcare (Greenwood et al., 2017). Information should thus be a major priority in planning and responding to crises, and is delineated in major guidance documents (e.g. Sphere Association, 2018). Moreover, the experience of populations affected by crises underlines the importance of information sharing (Harvard Humanitarian Initiative, 2011; Santos-Hernández and Morrow, 2013).

Sandvik, Jacobsen and Macdonald have noted that during crises information distribution itself is uneven, and ... often becomes a source of inequality - in violation of core humanitarian principles...' (2017: 22). Such unevenness is influenced by languages and access to translation. A particular concern is that language barriers to information and communication reinforce marginalisation. Minority linguistic communities are likely to be at heightened risk of harm during a crisis for more reasons than having limited proficiency with majority languages or the language spoken by aid responders. As TWB reported in relation to the conflict-affected Nigerian states of Borno, Yobe and Adamawa in 2017:

The [linguistic] difficulties described affect both operational effectiveness and accountability, from the inclusiveness of needs assessments and feedback mechanisms to the provision of services and the implementation of behavior change campaigns. Confidentiality and conflict-sensitivity are impaired when not everyone can speak for themselves. Organizations were also concerned that the language barriers are impeding their capacity to communicate effectively with conflict-affected groups on the nuances of key concepts (for instance around protection or mental health), and important technical distinctions (e.g. between categories of explosive remnants of war, each requiring specific safe behaviors from civilians). (TWB, 2017a)

Overcoming language barriers is more difficult for people who speak so-called 'low-resource languages' (e.g. Quechua). ${ }^{6}$ Trained translators with the requisite language skills are less likely to be available. Technological solutions are also less feasible. For example, MT generally relies upon the availability of already translated digitised texts to train each system. The Creole-to-English MT system in Haiti was only possible because of previously translated texts (though limited in number), including the Bible and data from a Carnegie Mellon University speech-to-speech research project conducted in the 1990s.

The consequences of limited understanding, possibly caused by inadequate translation, can be serious: populations may not heed directions to flee a danger area or may be deprived of services because they do not understand how to access them. Significantly, language barriers hindered the participation of local organisations in coordination meetings and networks of humanitarian responders in places such as Haiti (Kirsch et al., 2012), Afghanistan (De Ford Gonzáles et al., 2016) and Bangladesh (TWB, 2017b). The effects of such isolation are pernicious, 
with consequences for the effectiveness and sustainability of interventions. If groups feel excluded or isolated, relationships may be damaged and trust undermined. Moreover, poor communication with crisis-affected communities can cut off potentially valuable sources of indepth local knowledge and information (Munro, 2013).

\section{Language Translation as an Ethical Obligation during Humanitarian Crises}

The examples noted above, and many others, show that provision of adequate translation services during crises is ethically justified by the potential benefits provided and the possible harms avoided. It also demonstrates respect for linguistic minority populations caught up in crisis. Translation is essential to good communication and attention to the needs and values of different groups in contexts of linguistic and cultural diversity. It is therefore linked to Article 5 of the Code of Conduct for the International Red Cross and Red Crescent Movement and NGOs in Disaster Relief (IFRC, 1995): 'We shall respect culture and custom.' Access to translation may also be necessary to follow through on several other articles of the Code of Conduct, including 'we shall attempt to build disaster response on local capacities' (Article 6) and 'ways shall be found to involve programme beneficiaries in the management of relief aid' (Article 7). Accurate communication respects people's autonomy and promotes informed decision-making. Foreign-language skills are often better among those with higher incomes and greater access to education, and therefore adequate translation services can prevent pre-existing discrimination or inequalities from further excluding some members of affected communities. ${ }^{7}$ Justice supports the provision of translation services where language barriers and inadequate translation contribute to inequitable resource distribution. Otherwise, persons who do not speak, read or write in the languages understood by responders or privileged for communication in the crisis are at significant risk of being excluded or treated inequitably, threatening the humanitarian principle of impartiality. Similarly, the principle of solidarity highlights the importance of consultation, shared suffering and other connections (Slim, 1997) which require the sort of communication that translation and interpretation allow. In the development sector, a lack of translation can exclude certain groups from even applying for funding to international NGOs (Crack et al., 2018). Translation is also seen as time- and resource-intensive (Cadwell, 2016). Humanitarian or government agencies may assign it lower priority than other interventions. Nonetheless, translation should not be examined purely in terms of efficiency or cost, as it is an important means of upholding the dignity removing feelings of disadvantage among those working in aid organisations who are not from the dominant (typically Anglophone) linguistic culture, and promoting the development of trust between involved parties (Crack et al., 2018). The scarcity and urgency that characterise humanitarian settings lead to a second ethical issue related to distributive justice: allocating limited resources.

\section{Priority Setting for Translation Initiatives amid Other Pressing Humanitarian Goals}

How translation ought to be prioritised relative to other humanitarian activities is a challenging question. Answers will vary depending on the stage or scale of the crisis, the available budget and the linguistic context of the communities involved. Any analysis should start by recognising the harms of exclusion and marginalisation that arise when translation is unavailable, and noting the contribution of translation towards inclusion, trustbuilding, operational effectiveness and sustainability. Translation facilitates more accurate needs estimations and reduces the losses caused by language barriers. This attention is especially important (and challenging) since linguistic and intercultural mediation is not always clearly understood by humanitarians who may have 'conceptualized interpretation as a largely logistical issue, akin to booking flights, travel permits or a driver' (Wright, 2018: 13) and therefore of low priority. Organisations need to develop mechanisms to help them assess how to prioritise translation relative to other needs that require resources. However, these assessments are challenging because, for example, the impact of lacking vaccinations is easier to quantify than the lack of information in specific languages. To address such challenges, representatives from the affected linguistic and cultural groups should be included in these discussions and their concerns and proposals addressed in resulting guidelines and procedures. Humanitarian organisations may need training to raise their awareness of the challenges and opportunities with translation. Similarly, university courses in international development or humanitarian studies should address translation, since they have been found to regularly omit or give a low profile to the role of language and culture (Crack et al., 2018).

\section{Intersections between the Ethics of Crisis Translation and Humanitarian Ethics}

Language and its translation are ethical concerns in humanitarian action. They are linked to justice in information distribution and the capacity for two-way communication among crisis responders, and between local populations and responders. As well as avoiding various harms, linguistic mediation supports other values held to be important by humanitarian actors, 
including inclusivity, accountability, dignity, community engagement and respect (Crack et al., 2018). The ethics of crisis translation also provides a distinct angle for considering the wider field of humanitarian ethics.

\section{Insights from the Ethics of Crisis Translation for Humanitarian Ethics More Broadly}

At its root, humanitarian ethics is grounded in commitments to uphold dignity and enact justice in providing services to populations affected by crises. Justice is enacted through impartial aid to meet basic needs and in ways that respect people and their rights. Concerns for upholding the dignity of affected communities are linked to the acknowledgement of shared humanity among recipients and providers of aid despite steep inequalities (Slim, 2015; Hunt et al., 2014). Translation and linguistic mediation present distinctive points of view on both these dimensions of humanitarian ethics. The philosopher and theologian Paul Ricoeur examined the ethics of translation and suggested that translation offers a particularly salient illustration of ethical engagement. We take inspiration from this perspective, which sees translation as not a means just to communicate across the divides of languages but also to allow deeper ethical engagement: an ethics of exchange (O'Mathúna and Hunt, 2019). Writing about the act of translation, Ricoeur articulated the concept of linguistic hospitality as an 'act of inhabiting the word of the Other, paralleled by the act of receiving the word of the Other into one's own home, one's own dwelling' (2007: xvi). Humanitarian aid entails overcoming distances: geographic distances as national or international responders travel to a locale experiencing crisis, but also social, cultural, political and narrative distances due to the vastly divergent experiences of people caught up in crises. A key challenge for humanitarian ethics is to take account both of the steep asymmetries between those seeking to provide assistance (though not always succeeding) and others who require help due to a crisis, and the fundamental equality of all human beings. Ricoeur's articulation of linguistic hospitality suggests important considerations that may not be immediately apparent: that responders from outside a community are guests as well as helpers, that communities have resources that responders may lack (e.g. capacities in local language, cultural expertise, understanding of local geographies and customs) and that mutual exchange is both possible and necessary as a basis for respect and trust. From this perspective, translation is not just a narrowing of linguistic distances but a place of meeting. Footitt suggests that Ricoeur's analysis points to the potential for translation as not merely transactional (e.g. allowing NGOs to 'give voice' to local stories, listening to aid recipients' feedback or facilitating accountability mechanisms) but also a means of instantiating intercultural openness and reflecting 'a paradigm of conversation, transnational exchange and narrative plurality' (Footitt, 2017: 521).
The second insight we draw for humanitarian ethics relates to questions of justice and fairness. In humanitarian ethics, emphasis is placed on the availability and distribution of assistance and resources during crisis. Less attention has been given to epistemic justice and power asymmetries in the 'credibility economy' (Fricker, 2007) that exists in a humanitarian crisis. In humanitarian aid, an epistemic privilege is associated with the principal language(s) in which aid is coordinated and administered. In practice, this is often English but might be other languages in other contexts. Language barriers within the humanitarian response, especially where effective translation is not available, can lead to significant limitations in how people participate in knowledge pooling and might devalue the knowledge held by some individuals or communities (i.e. seen as less credible) due to their being less fluent in the dominant language, a situation described by Fricker as testimonial injustice (2007). Certainly, epistemic injustice pertains to more than language and may arise due to unacknowledged prejudices (e.g. disvaluing the credibility of experiences recounted by women). Discussions about how language mediates the pooling of knowledge and credibility of different actors in the humanitarian space are instructive in drawing attention to the presence of epistemic privileges and injustices, and opportunities to address them, including the development of epistemic humility on the part of humanitarian practitioners. Epistemic humility is 'manifested through greater language sensitivity and metalinguistic awareness, particularly among those who are accorded greater epistemic authority' (Peled, 2018: 361). Otherwise, individuals who are marginalised and who already suffer disproportionately during disasters and crises will experience further injustice rather than experience the dignity and empowerment which translation can provide (O’Mathúna, 2018).

The first three layers of ethical issues drew attention to ethical obligations and justice regarding translation during crises when resources are scarce, and links between humanitarian ethics and the ethics of crisis translation. Before considering ethical dimensions of developing, implementing, evaluating and diffusing innovative crisis translation products and processes, we first briefly examine some emergent ICTs and strategies.

\section{Innovations in Crisis Translation}

Innovative approaches for crisis translation include technological developments like translation memory, glossary apps and MT engines (O'Brien, 2019). ${ }^{8}$ A translation memory is specialist software that allows a translator to reuse previous translations easily and speedily: as the translator types, the software proposes translations previously stored in its database. These technologies are standard in commercial translation 
settings and aim to increase translation quality while reducing time and costs. Their application in crisis settings is relatively new. For example, TWB recently implemented a customised version of a commercial translation-memory platform for use by volunteer translators (Zetsche, 2017). One aim of the EU-funded Interact project ${ }^{9}$ is to improve MT engagement with low-resource languages by investigating techniques for 'pivoting' from one language through an intermediary language to a third language. For instance, an MT system that translates directly from Portuguese to Swahili may not be feasible if few texts translate from Portuguese directly to Swahili. However, if translated text exists from Portuguese to English and from English to Swahili, English can be used as a 'pivot language' for MT. Many challenges exist with such technological responses, including the lack of 'big' linguistic data to build translation engines, the likely poor quality of the translations initially produced by this approach due to natural-language processing challenges, and the lack of linguistic expertise to edit the outputs. Furthermore, these solutions normally require access to the internet, which may be impossible in some crises. Innovative solutions to these constraints may require looking to older technological solutions, such as building linguistic rulesbased MT engines for specific language pairs that work offline, as TWB has done for two Kurdish languages Kurmanji and Sorani - with the help of people from those language communities (RWS, 2017).

Designers and implementers need to overcome many technical issues with such innovations. Additionally, ethical challenges arise. Values-sensitive approaches to humanitarian innovation recommend identifying ethical questions as innovations are conceived, developed, implemented and diffused (Smith, forthcoming). We propose that all stakeholders (e.g. humanitarian organisations, policymakers, technologists, commercial developers, governments and affected communities) should demonstrate a moral posture of attentiveness to how values are upheld, engaged with or challenged throughout the innovation process.

The innovative strategies available for crisis translation each have merits and limitations from technical, operational and ethical perspectives. When contemplating an innovation programme involving translation, stakeholders should also seek to anticipate ethical implications of the innovation.

\section{The Values Likely to Be Upheld or Challenged when Particular Innovations Are Pursued}

Ethical considerations related to emergent humanitarian ICTs in the health sector include ensuring accuracy, protecting privacy and security, responding to inequalities, demonstrating respect for individuals and communities, protecting relationships and addressing expectations that cannot be met (Hunt et al., 2016).
Many of these concerns are relevant for assessing the ethical implications of innovative products or processes for crisis translation. To take a non-technological example, an innovation project that relies on citizen volunteers (i.e. volunteers drawn from an affected or supportive community but who are not necessarily professional translators) should consider elements such as ensuring translations are of sufficient quality (and avoiding potential harms from inaccuracies), the advantage of using people already in place (therefore not further burdening local capacity by bringing in outsiders) and using people with greater knowledge of local cultural and social realities, as well as possible harms from using family members and, in particular, children as translators and interpreters (O’Mathúna, forthcoming). For example, children of migrants adapt more quickly to local languages and cultures and may be asked to translate in health, legal, and administrative contexts. Such mediation raises ethical questions as it could expose children to difficult discussions, depending on their developmental age, and could compromise the normal relationships and power dynamics within the family or community (Antonini, 2015).

Values of participation and engagement are highly relevant to innovation processes in humanitarian settings (Betts and Bloom, 2014). Active involvement of local stakeholders demonstrates respect and promotes their dignity. Valuing their knowledge and insight also upholds epistemic justice. Where possible, end users should be engaged in discussions as the innovative process or product is being developed. This consultation should prioritise members of communities that have experience of or are likely to experience a crisis, not just engage with humanitarian workers. For example, in developing MT engines for specific language pairs, developers might conclude that the MT tool overcomes the language barrier'. However, experience from the commercial sector demonstrates that MT alone is incomplete, sometimes inappropriate and, if introduced without consulting end users, more likely to be resented or rejected (Cadwell, 2017). TWB's involvement of Kurmanji and Sorani speakers in MT development exemplifies good community engagement in such technological innovation (RWS, 2017).

Innovations in the humanitarian sector often influence relationships, such as how the shift from 'face to face' to 'face to screen' interactions may impact humanitarian relationships (Donini and Maxwell, 2013). Increasing linguistic mediation could neutralise negative impacts and even strengthen relationships among humanitarian responders, local actors and communities affected by crises, especially if this engagement is characterised by a posture of 'linguistic hospitality' (Ricoeur, 2007). A useful guiding principle is to prioritise integration over disruption (Munro, 2013). Translation innovations should integrate 
with existing reporting systems, information requirements and communication conventions and channels; they should be deployed through partnerships with trusted actors; and they should be used, in particular, to involve and empower crisis-affected communities in their own response and recovery.

Crisis translation innovations often need to balance accuracy and timeliness. The accepted premise is that a human translator with the right qualifications, experience and tools will do a good job but take longer than MT. On the other hand, MT will have variable quality depending on factors like language pair, translation direction and content type. Each humanitarian crisis raises difficult questions about the priority of quality or speed. Decisions must consider the content to be translated, its criticality, sensitivity and level of perishability, the languages required, the level of performance of the MT system and the availability of linguists. All these factors suggest that preparation and advance testing are essential, something that may appear to be a luxury in humanitarian crises. However, testing and evaluation can be carried out in non-crisis settings initially. Methods of estimating quality are another technological innovation by which MT output quality is measured automatically by the MT system itself (Blatz et al., 2004). Estimates can be produced for document, sentence, phrase and even word level, and these measures could be used to triage highquality from low-quality output. However, this technological innovation is still relatively novel, approximate and untested for the humanitarian domain.

Another concern is potential bias in MT systems, possibly creating or contributing to inequities. Harm may result when translating between languages where non-specific pronouns are converted to gender-specific ones. For example, if gender-neutral information related to an infectious disease is translated with gender-specific pronouns this may be interpreted to mean that only men or only women are susceptible. Furthermore, MT could be used maliciously, as when a powerful group might seek to spread disinformation.

Crisis translation innovations carry the added risk of facilitating communication that people are unable to act on, and of creating expectations which cannot be met. For instance, emergency messages could be gathered and translated from a crisis-affected population without anyone being able to act on the messages gathered. This could erode trust within the community (CDAC Network, 2018). Indeed, one recommendation from the Mission 4636 SMS translation project in Haiti was: 'Do not elicit information for which there is not the capacity to respond' (Munro, 2013: 257). Crisis translation efforts are best paired with existing response efforts and should complement on-the-ground capacity as determined through relationships established and maintained prior to the acute response phase. After an innovation is rolled out in the 'living laboratory' of humanitarian action, its impact should be evaluated to determine whether this differed from what was anticipated during design and development.

\section{Addressing Unintended Consequences of Inno- vations and Sustaining Successful Innovations}

Evaluating how an innovation responds to operational realities and institutional needs is likely to yield insights. Opportunities will arise to reflect on whether usage matches espoused ethical commitments. For example, Madianou and colleagues reported that an NGO was systematically collecting social-media responses from project recipients, translating them from a local dialect into Tagalog and then into English (Madianou et al., 2016). However, the information was not used to promote accountability to local communities as intended or to improve programmes; rather, it was used to prepare head-office reports aimed at donors, leading to translation being part of a process linked to the 'appearance of accountability' but not accountability itself (Madianou et al., 2016: 1). Another example arose with the use of voluntary workers. Munro (2013) described dissatisfaction among volunteers in Haiti who were asked after the crisis by external actors to translate non-emergency-related texts for no payment. An unpaid, voluntary innovation became one where translators felt taken for granted or even exploited. If information is a form of aid, then it comes at a cost, just like water, food, medicine and other supplies, and the free provision of information should not be assumed, even in a crisis. Indeed, the long-term needs of the crisis-affected community might be served better by NGOs and other actors providing paid work to successful networks of translation volunteers that could be scaled up in sustainable ways during recovery.

Humanitarian responses are typically focused on the immediate needs of a community in crisis. In the acute phase, limited attention is paid to the long-term impacts of how aid is organised and implemented. Brun described this focus on the crisis as humanitarians being 'stuck in the present' (2016: 393). Innovation processes should seek to maximise benefits for local populations in a sustainable manner, raising questions about sustained availability. For instance, solutions could be rolled out in a careful and sustainable way by first identifying potential language needs, building linguistic resources for terminology and MT, editing this MT output using professional translators when available, or crowdsourcing when not, and improving the quality through storing the translations in a shared, online, translation-memory system for longer-term use. Ideally, open training resources would be available to crowdsourced volunteers, all technology would be accessible and open, and dedicated 
personnel would manage and maintain the technology, resources and people.

An important consideration for innovation in the humanitarian space is how the public good will be promoted by sharing insights and new approaches that are promising. Sharing these can be challenging in the humanitarian sector. A tendency exists to look for in-house solutions (Hestbaek, 2017). Sharing some information can raise concerns about security and privacy. Open-access maps could be misused, for example, to oppress or target protesters in politically unstable situations. Innovations developed collaboratively with for-profit companies also raise questions related to proprietary knowledge, intellectual property and conflicts of interest. This challenge is increasing as private-sector companies are showing more interest in humanitarian innovation, motivated both by corporate social responsibility and because commercially valuable data is available in these settings (CDAC Network, 2018). To avoid confusion or conflict, clear plans and commitments for sharing or not sharing successful innovations should be established from the outset.

\section{Conclusion}

Translation is ethically important in creating opportunities for communication and exchange across linguistic communities, and among humanitarian responders, government agencies and local communities. It also upholds commitments to justice and impartiality, addresses the needs of groups that are especially vulnerable and facilitates accountability and community engagement, while demonstrating respect and promoting the dignity of individuals and groups affected by crisis. We have discussed how justice must be addressed in considering the priority that translation services should receive relative to other pressing needs during a crisis. This discussion of the ethics of crisis translation links to two dimensions of humanitarian ethics more broadly. Ricoeur's concept of linguistic hospitality suggests how relationships in humanitarian settings often span social, cultural, geographic and linguistic distances, and should be conceived not merely as transactional but through an ethic of exchange that also acknowledges inherent asymmetry between those who require and those who provide assistance during a crisis. The second dimension relates to the relationship between knowledge and justice. Language and barriers to understanding point to the importance of responding to epistemic privilege and testimonial injustice in how humanitarian aid is organised and provided, including practising epistemic humility. To improve access, speed and accuracy of translation, innovative products and humanitarian contexts. Ethical attention is also required throughout their development and deployment to ensure that innovations support the ethical commitments of involved stakeholders, including humanitarian principles. Ethical humanitarian action requires responsiveness to the linguistic mediation of relationships and information sharing, and the potential for injustices linked to language.

\section{Notes}

1 This research has been made possible by a James M Flaherty Research Scholarship from the Ireland Canada University Foundation, with the assistance of the Government of Canada/avec l'appui du gouvernement du Canada, that was awarded to Matthew Hunt and through which he was Visiting Researcher at Dublin City University in March 2018. The paper also results from collaborative work that has received funding from the European Union's Horizon 2020 research and innovation programme under the Marie Skłodowska-Curie grant agreement No 734211. Matthew Hunt holds a Research Scholar Award from the Fonds de Recherche du Québec-Santé.

2 www.unige.ch/inzone/who-we-are/ (accessed 6 January 2020).

3 http://inzone.unige.ch/rrm/ (password access required) (accessed 6 January 2020).

4 https://translatorswithoutborders.org/ (accessed 6 January 2020). Of note here is the fact that the traditional differentiators between written and oral translation become blurred in a humanitarian or emergency response setting, something that needs to be taken into account in innovations that contribute to the provision of translation, understood in its broadest sense.

5 http://red-t.org/ (accessed 6 January 2020).

6 A 'language resource' is a set of speech or language data and descriptions in machine-readable form (www.elra. info/en/about/what-language-resource/ (accessed 6 January 2020)). The definition of a 'low resource' language is, however, not agreed upon, with criteria varying from demographic to linguistic to level of resources available. See Cieri et al. (2016) for further discussion.

It should be acknowledged that not heeding directions may be attributed to other reasons, such as mistrust of the information source. We do not examine this additional, complex dimension here.

7 Many studies show a correlation between higher socioeconomic status and higher student achievement in general (see, e.g. Calvo and Bialystok, 2014). Recent studies focus on socio-economic effects on foreign-language skills in particular, showing that those from higher-income backgrounds are advantaged in relation to attaining higher foreign-language skills (e.g. Rascón Moreno and Bretones Callejas, 2018; Shin and So, 2018). 
8 Most of the innovations listed here are for written text and assume a basic level of literacy. However, crises often hit communities with low literacy levels and/or cultural preferences for speech communication (O'Brien and Cadwell, 2017). Despite much progress with speech technology in general, and speech-to-text specifically, innovations for crisis scenarios that involve high-quality speech translation are still limited.

9 https://sites.google.com/view/crisistranslation/home?authuser=0 (accessed 6 January 2020).

\section{Bibliography}

Aitsi-Selmi, A., Murray, V., Wannous, C. et al. (2016), 'Reflections on a Science and Technology Agenda for 21st Century Disaster Risk Reduction: Based on the Scientific Content of the 2016 UNISDR Science and Technology Conference on the Implementation of the Sendai Framework for Disaster Risk Reduction 2015-2030', International Journal of Disaster Risk Science, 7:1, 1-29.

Antonini, R. (2015), 'Child Language Brokering', in Pöchhacker, F. (ed.), Routledge Encyclopedia of Interpreting Studies (London: Routledge), p. 48.

Blatz, J., Fitzgerald, E., Foster, G. et al. (2004), 'Confidence Estimation for Machine Translation', Proceedings of the 20th International Conference on Computational Linguistics, pp. 315-21.

Betts, A. and Bloom, L. (2014), Humanitarian Innovation: The State of the Art, www.unocha.org/publication/policy-briefs-studies/humanitarian-innovation-state-art (accessed 18 October 2018).

Brun, C. (2016), 'There Is No Future in Humanitarianism: Emergency, Temporality and Protracted Displacement', History and Anthropology, 27:4, 393-410.

Cadwell, P. (2016), 'A Place for Translation Technologies in Disaster Settings: The Case of the 2011 Great East Japan Earthquake', in O'Hagan, M. and Zhang, Q. (eds), Conflict and Communication: A Changing Asia in a Globalising World (New York: Nova Science Publishers), 169-94.

Cadwell, P., O'Brien, S. and Teixeira, C. (2017), 'Resistance and Accommodation: Factors for the (Non-)Adoption of Machine Translation among Professional Translators', Perspectives: Studies in Translation Theory and Practice, 26:3, 301-21.

Calvo, A. and Bialystok, E. (2014), 'Independent Effects of Bilingualism and Socioeconomic Status on Language Ability and Executive Functioning', Cognition, 130:3, 278-88.

CDAC Network (2018), 'Digital Inclusion and Community Voices: Stepping over the Humanitarian-Development Divide', www. cdacnetwork.org/contentAsset/raw-data/5c226888-c5ec-44b2-8bbf9d663fff9d04/attachedFile1 (accessed 17 October 2018).

Cieri, C., Maxwell, M., Strassl, S. and Tracey, J. (2016), 'Selection Criteria for Low Resource Language Programs', in Calzolari, N. et al. (eds), Proceedings of the Tenth International Conference on Language Resources and Evaluation (Portorož, Slovenia), pp. 4543-9.

Crack, A., Footitt, H. and Tesseur, W. (2018), Respecting Communities in International Development: Languages and Cultural Understanding, www.reading.ac.uk/web/files/modern-languages-and-european-studies/ Listening_zones_report_-EN.pdf (accessed 18 October 2018).

De Ford González, P., Cuervo, J., Khan, F. and Johnson, S. (2016), 'Evaluation and Optimization of Humanitarian Aid Using Data and Network Sciences: Case-study of Afghanistan in 2015' (PhD thesis), University of Warwick.

Donini, A. and Maxwell, D. (2013), 'From Face-to-face to Face-toscreen: Remote Management, Effectiveness and Accountability of
Humanitarian Action in Insecure Environments', International Review of the Red Cross, 95:890, 383-413.

Fischer, H. (2008), Response to Disaster: Fact versus Fiction and Its Perpetuation: The Sociology of Disaster (Lanham, MD: University Press of America).

Footitt, H. (2017), 'International Aid and Development: Hearing Multilingualism, Learning from Intercultural Encounters in the History of OxfamGB', Language and Intercultural Communication, $17: 4,518-33$.

Fricker, M. (2007), Epistemic Injustice: Power and the Ethics of Knowing (Oxford: Oxford University Press).

Ghandour-Demiri, N. (2017), Language and Comprehension Barriers in Greece's Migration Crisis, https://translatorswithoutborders.org/wpcontent/uploads/2017/07/Language-Comprehension-barriers.pdf (accessed 12 June 2019).

Greenwood, F., Howarth, C., Escudero Poole, D., Raymond, N. A. and Scarnecchia, D. P. (2017), The Signal Code: A Human Rights Approach to Information during Crisis, https://hhi.harvard.edu/sites/default/files/ publications/signalcode_final.pdf (accessed 18 October 2018).

Harvard Humanitarian Initiative (2011), Disaster Relief 2.0: The Future of Information Sharing in Humanitarian Emergencies (Washington, DC and Newbury: UN Foundation and Vodafone Foundation Technology Partnership).

Hasan, M. (2018), The Language Lesson: What We've Learned about Communicating with Rohingya Refugees, https://translatorswithoutborders.org/wp-content/uploads/2018/12/TWB_Bangladesh_Comprehension_Study_Nov2018.pdf (accessed 12 June 2019).

Hestbaek, K. (2017), '3 Things Faecal Sludge Can Teach Us about Humanitarian Innovation', Elrha's Humanitarian Innovation Fund blog, www.elrha.org/news/3-things-faecal-sludge-can-teach-ushumanitarian-innovation/ (accessed 18 October 2018).

Hunt, M., Pringle, J., Christen, M. et al. (2016), 'Ethics of Emergent Information and Communication Technology Applications in Humanitarian Medical Assistance', International Health, 8:4, 239-45.

Hunt, M. R., Schwartz, L., Sinding, C. and Elit, L. (2014), 'The Ethics of Engaged Presence: A Framework for Health Professionals in Humanitarian Assistance and Development Work', Developing World Bioethics, 14:1, 47-55.

IFRC (1995), The Code of Conduct for the International Red Cross and Red Crescent Movement and Non-governmental Organizations (NGOs) in Disaster Relief, www.ifrc.org/Global/Publications/disasters/codeof-conduct/code-english.pdf (accessed 10 June 2019).

Kirsch, T., Sauer, L. and Sapir, D. G. (2012), 'Analysis of the International and US Response to the Haiti Earthquake: Recommendations for Change', Disaster Medicine and Public Health Preparedness, 6:3, 200-8.

Lewis, W., Munro, R. and Vogel, S. (2011), 'Crisis MT: Developing a Cookbook for MT in Crisis Situations', Proceedings of the 6th Workshop on Statistical Machine Translation, pp. 501-11.

Madianou, M., Ong, J. C., Longboan, L. and Cornelio, J. C. (2016), 'The Appearance of Accountability: Communication Technologies and Power Asymmetries in Humanitarian Aid and Disaster Recovery', Journal of Communication, 66:6, 960-81.

Munro, R. (2013), 'Crowdsourcing and the Crisis-affected Community: Lessons Learned and Looking Forward from Mission 4636', Journal of Information Retrieval, 16:2, 210-66.

Nelson, A., Sigal, I. and Zambrano, D. (2010). Media, Information Systems and Communities: Lessons from Haiti, John S. and James L. Knight Foundation, https://knightfoundation.org/reports/media-informationsystem-and-communities-lessons-h (accessed 18 October 2018).

O’Brien, S. (2019), 'Translation Technology and Disaster Management', in O'Hagan, M. (ed), The Routledge Handbook of Translation and Technology (Abingdon: Routledge), 304-18.

O'Brien, S., Federici, F. M., Cadwell, P., Marlowe, J. and Gerber, B. (2018), 'Language Translation during Disaster: A Comparative 
Analysis of Five National Approaches', International Journal of Disaster Risk Reduction, 31, 627-36.

O’Mathúna, D. P. (2018), 'Humanitarian Ethics: From Dignity and Solidarity to Response and Research', in Lysaught, M. T. and McCarthy, M. (eds), Catholic Bioethics and Social Justice: The Praxis of US Health Care in a Globalized World (Collegeville, MN: Liturgical Press), 343-57.

O’Mathúna, D. P. and Hunt, M. R. (2019), 'Ethics and Crisis Translation: Insights from the Work of Paul Ricoeur', Disaster Prevention and Management: An International Journal, www.emerald.com/insight/ content/doi/10.1108/DPM-01-2019-0006/full/html (accessed 6 January 2020).

O’Mathúna, D. P., Parra Escartín, C., Roche, P. and Marlowe, J. (forthcoming), 'Engaging Citizen Translators in Disasters: Virtue Ethics in Response to Ethical Challenges', Translation and Interpreting Studies, 15(1).

Peled, Y. (2018). 'Language Barriers and Epistemic Injustice in Healthcare Settings', Bioethics, 32:6, 360-7.

Rascón Moreno, D. and Bretones Callejas, C. M. (2018), 'Socioeconomic Status and Its Impact on Language and Content Attainment in CLIL Contexts', Porta Linguarum, 29, 115-35.

Ricoeur, P. (2007), On Translation (New York: Routledge).

RWS (2017), 'Language Tech in the Nonprofit World: Interview with Mirko Plitt', RWS Moravia, 5 September, https://info.moravia.com/ blog/language-tech-in-the-nonprofit-world-interview-with-mirko-plitt (accessed 25 October 2018).

Sandvik, K. B. (2014), 'Humanitarian Innovation, Humanitarian Renewal?', Forced Migration Review, a00101s1, 25-7.

Sandvik, K. B., Jacobsen, K. L. and McDonald, S. M. (2017), 'Do No Harm: A Taxonomy of the Challenges of Humanitarian Experimentation', International Review of the Red Cross, 99:904, 319-44.

Santos-Hernández, J. M. and Morrow, H. B. (2013), 'Language and Literacy', in Thomas, D. S. K., Phillips, B. D., Lovekamp, W. E. and Fothergill, A. (eds), Social Vulnerability to Disasters (Boca Raton, FL, London and New York: CRC Press), pp. 265-80.

Seeger, M. W. (2006), 'Best Practices in Crisis Communication: An Expert Panel Process', Journal of Applied Communication Research, $34: 3,232-44$
Sellnow, T. L. and Seeger, M.W. (2013), Theorizing Crisis Communication (Chichester: Wiley-Blackwell).

Shin, H. W. and So, Y. (2018), 'The Moderating Role of Socioeconomic Status on Motivation of Adolescents' Foreign Language Learning Strategy Use', System, 73, 71-9.

Slim, H. (1997), 'Relief Agencies and Moral Standing in War: Principles of Humanity, Neutrality, Impartiality and Solidarity', Development in Practice, 7, 342-52.

Slim, H. (2015), Humanitarian Ethics: A Guide to the Morality of Aid in War and Disaster (Oxford: Oxford University Press).

Smith, A., Pringle, J. and Hunt, M. (forthcoming), 'Value-sensitive Design for Humanitarian Action: Integrating Ethical Analysis for Information and Communication Technology Innovations', in Messelken, D. and Winkler, D. (eds), Ethics of Military and Humanitarian Enhancement, Innovation and Research (Springer: Dordrecht).

Sphere Association (2018), The Sphere Handbook: Humanitarian Charter and Minimum Standards in Humanitarian Response (Geneva: Sphere Association), www.spherestandards.org/handbook-2018/ (accessed 10 June 2019).

Steets, J., Sagmeister, E. and Ruppert, L. (2016), 'Eyes and Ears on the Ground: Monitoring Aid in Insecure Environments', Berlin, Global Public Policy Institute, Report from the Secure Access in Volatile Environments (SAVE) Research Programme, www.gppi.net/fileadmin/ user_upload/media/pub/2016/SAVE_2016_Monitoring_aid_in_insecure_environments.pdf (accessed 18 October 2018).

TWB (2017a), 'Language Barriers in the Humanitarian Response in Northeastern Nigeria: Initial Assessment', https://translatorswithoutborders. org/wp-content/uploads/2017/04/Language-barriers-in-the-humanitarianresponse-in-north-eastern-Nigeria.pdf (accessed 18 October 2018).

TWB (2017b), 'Rohingya Zuban: A Translators without Borders Rapid Assessment in Cox's Bazaar Refugee Response', www.arcgis.com/ apps/Cascade/index.html?appid $=683 \mathrm{a} 58 \mathrm{~b} 07 \mathrm{dba} 4 \mathrm{db} 189297061 \mathrm{~b} 4 \mathrm{f8c}$ d40\&utm (accessed 18 October 2018).

Wright, K. (2018), 'Helping Our Beneficiaries Tell Their Own Stories? International Aid Agencies and the Politics of Voice within News Production', Global Media and Communication, 14:1, 85-102.

Zetsche, J. (2017), 'Translators without Borders and Technology', The ATA Chronicle, July/August, 27-8. 